\title{
Epidemiology and Surveillance of Hepatocellular Carcinoma
}

\author{
Do Young Kim Kwang-Hyub Han
}

Department of Internal Medicine, Yonsei University College of Medicine, Liver Cirrhosis Clinical Research Center, Liver Cancer Early Diagnosis Clinic, Severance Hospital, Seoul, Korea

\author{
Key Words \\ Biomarker · Epidemiology · Hepatocellular carcinoma · Surveillance · Ultrasound
}

\begin{abstract}
Hepatocellular carcinoma (HCC) is one of the most frequently occurring malignancies and has a high mortality rate. The incidence of HCC differs greatly according to the geographic area. East and Southeast Asia, as well as middle and West Africas have the highest prevalence of HCC. The risk factors for developing HCC are well known and include cirrhosis, hepatitis $B$ virus (HBV) infection, hepatitis C virus (HCV) infection, alcohol consumption, smoking, diabetes, and nonalcoholic steatohepatitis. Cirrhosis is the most significant risk factor, and there is a correlation between the degree of noninvasively measured liver fibrosis and the risk of HCC occurrence. HBV exerts carcinogenic effects by several mechanisms, including host genome integration, and studies have revealed that HBV replication predicts HCC development. HCV induces multistep carcinogenesis from inflammation, to fibrosis and liver cancer. $\mathrm{HCC}$ is an appropriate target for surveillance programs for early cancer detection. Currently, liver ultrasonography (US) combined with serum alpha-fetoprotein (AFP, a biomarker of HCC) measurement every 6 months is the standard method of HCC surveillance. Although US is the most widely used tool, its sensitivity in detecting early HCC (i.e., within the Milan criteria) during surveillance is only $63 \%$. AFP is the representative biomarker for both HCC surveillance and diagnosis; however, the unsatisfactory performance of AFP as a surveillance tool means that a novel biomarker or combination with other serum markers is required. Des-gammacarboxy prothrombin and AFP-L3 are candidate biomarkers that are complementary to AFP. The strategies of HCC surveillance vary in different countries according to the healthcare system, the resources available, and health insurance coverage. Many studies have shown that the rate of early cancer detection and rate of application of curative therapies were increased, as was the survival time, by HCC surveillance, which should now become a part of standard care, rather than just a recommendation. Improved US technology and the discovery of new biomarkers are necessary to make further progress in HCC surveillance.
\end{abstract}

Copyright $@ 2012$ S. Karger AG, Basel

Kwang-Hyub Han, MD

Department of Internal Medicine, Yonsei University College of Medicine, Liver Cirrhosis Clinical Research Center, Liver Cancer Early Diagnosis Clinic, Severance Hospital, 50 Yonsei-ro, Seodaemun-gu, Seoul 120-752 (Korea) Tel.+82 22228 1949, E-Mail gihankhys@yuhs.ac 


\section{Introduction}

Hepatocellular carcinoma (HCC) is the fifth most common cancer worldwide and causes significant public health problems, especially in association with chronic hepatitis $\mathrm{B}$ or $\mathrm{C}$. The observation that half of HCC cases and deaths are estimated to occur in China indicates that hepatitis B virus (HBV) infection plays a major carcinogenic role in global HCC epidemiology [1]. Moreover, the incidence of liver cancer is high not only in developing countries but has also been increasing among most racial and ethnic groups in developed countries, such as the United States, as a result of hepatitis C virus (HCV) infection and nonalcoholic steatohepatitis (NASH) [2]. Despite substantial progress in understanding of the molecular pathogenesis of HCC, imaging techniques, and novel therapies (including targeted drugs), the overall prognosis of HCC patients is still poor. Tumor multiplicity, frequent vascular invasion, and accompanying cirrhosis are clinical features of HCC that lead to unsatisfactory outcomes. High rates of tumor recurrence and resistance to chemotherapeutic agents also make the management of HCC challenging. The poor outcome of patients with HCC is attributed to late detection, with more than two-thirds of patients diagnosed at advanced stages of the disease [3]. However, a considerable improvement in survival has been observed (5-year survival up from $40 \%$ to $70 \%$ ) when patients are diagnosed at an early stage and receive potentially curative therapy in the form of liver transplantation, surgical resection, or tumor ablation [4]. The assumption common to all malignancies is that if a cancer can be detected at the incipient stage and its advance halted, we should be able to reduce the mortality associated with the disease [5]. Cancer screening is justified when the prevalence is high, the target population is readily identifiable, and the test adopted has high accuracy and is acceptable to the population. In this regard, HCC surveillance, i.e., the repeated application of screening in the at-risk population, is considered to be worthwhile in clinical practice. The aim of this article is to summarize the global epidemiology of HCC and to provide an update on HCC surveillance through a review of the recent literature.

\section{Epidemiology of HCC}

Approximately 748,300 new cases of HCC were diagnosed in 2008, and 695,900 patients died of the disease; these statistics underline the high mortality rate of this type of cancer [6]. In men, it is the fifth most frequently diagnosed cancer worldwide, but it is the second most frequent cause of cancer death. In women, HCC ranks as the seventh most commonly diagnosed cancer and the sixth leading cause of cancer-related death [7]. The incidence of HCC largely varies according to the geographic area, although it is usually higher in developing countries than in developed countries. East and Southeast Asia, as well as middle and West Africa, have the highest rates of HCC, whereas the rates are low in south-central and western Asia and northern and eastern Europe. The incidences in North Africa and Central America are at intermediate levels (fig. 1). HCC occurrence starts to rise from the age of 40 years and reaches a peak at around 70 years.

The global temporal trend of HCC incidence is not consistent. While the age-adjusted incidence rate of HCC has been decreasing in a few cities in China and Japan, where the main cause of HCC is HBV and HCV, respectively [8, 9], national registries show that the overall incidence of HCC increased, even in United States, between 1992 and 2008 [10]. 
Fig. 1. The incidence of hepatocellular carcinoma in different geographic regions (Source: GLOBOCAN 2008).

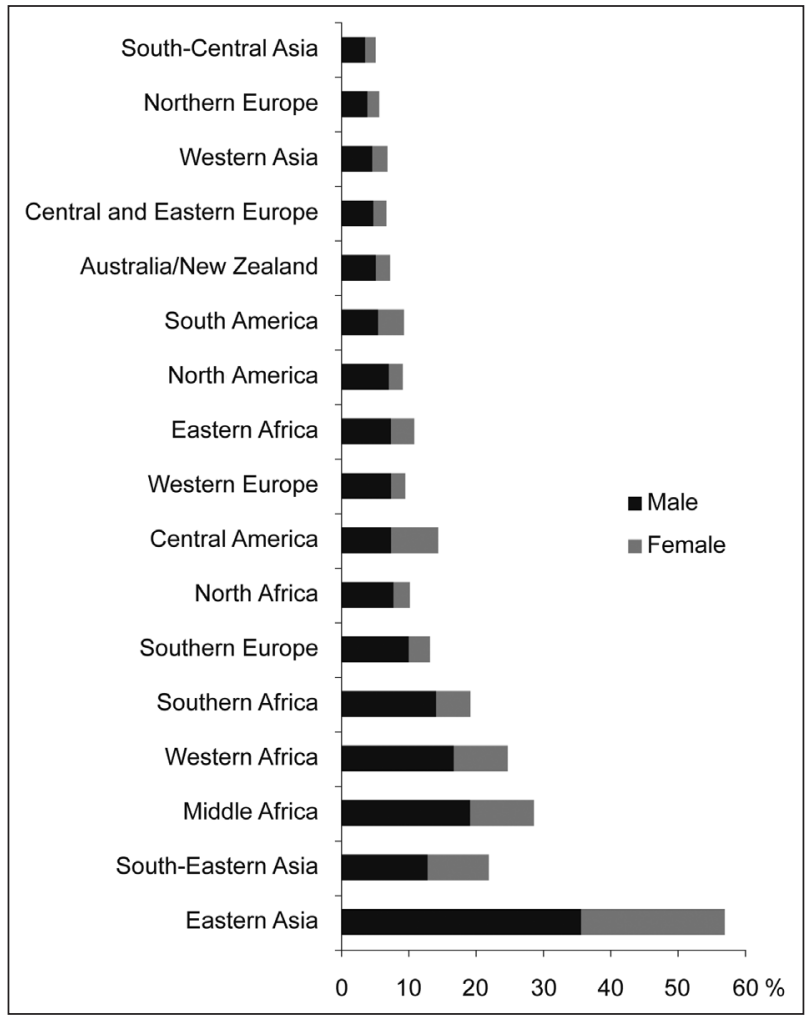

\section{Risk Factors of HCC}

In $70-90 \%$ of all cases, HCC develops against a background of chronic liver disease or inflammation and cirrhosis. Cirrhosis is recognized as the leading cause of HCC, and the annual risk of developing HCC is reported to be 3-8\% in HBV-related cirrhotic patients and $1-7 \%$ in HCV-related cirrhotic patients $[11,12]$. In a Korean 9-year prospective study of 4339 patients, cirrhosis was found to be the strongest predictor of HCC development [13]. In cirrhotic liver, activated hepatic stellate cells are responsive to such cytokines as plateletderived growth factor and transforming growth factor- $\beta$, which in turn activate both mitogen-activated protein kinase and phosphatidylinositol-3-kinase/Akt pathways, and this constitutes the signal cascade typically seen in hepatocarcinogenesis [14]. Furthermore, several lines of evidence suggest that stellate cells, which play a key role in cirrhosis, may harbor the potential to transdifferentiate into progenitor cells and are possibly linked to the development of HCC [15]. Based on the hypothesis that the degree or stage of fibrosis could be a linear predictor of the development of HCC, the correlation between baseline liver stiffness measurement (LSM) by transient elastography and HCC occurrence during follow-up was studied in $1130 \mathrm{HBV}$-infected patients. During the median follow-up of 30.7 months, the 3-year cumulative incidence rate of HCC was $5.98 \%$, and a higher LSM value ( $>8 \mathrm{kPa}$ ) was an independent predictor of HCC development. The HCC incidence was $23.9 \%$ in patients with $\mathrm{LSM} \geq 23 \mathrm{kPa}$, whereas it was only $1.3 \%$ in patients with LSM $<8 \mathrm{kPa}$ [16]. Although those findings need to be validated prospectively and in external cohorts, this study highlights the importance of advanced fibrosis (as measured noninvasively) in HCC development. Because most investigators include only Child-Pugh grade A or B cirrhotic patients in their surveillance programs, the effect of advanced cirrhosis (Child-Pugh grade C) on HCC occurrence remains unknown. Five-year disease-free survival following liver transplantation (LT) in 
HCC patients is approaching 75\% after the widespread application of the Milan criteria [17]. Consequently, the efficacy of surveillance for HCC requires further evaluation in patients with decompensated cirrhosis, since even early-stage HCC identified by surveillance in these patients can clearly lead to LT.

The epidemiological observation that global differences in the incidence of HCC coincide with the prevalence of HBV infection strongly suggests that HBV has a hepatocarcinogenic influence. In Asia and Africa, approximately $60 \%$ of all cases of HCC are related to chronic HBV infection [18]. Numerous studies have shown that the oncogenic role of HBV in liver cancer includes HBV DNA integration into the host genome, HBx protein transactivating several signaling pathways, and the relation between pre-S/S protein and endoplasmic reticulum stress/oxidative host DNA damage [19,20]. Accordingly, unlike the situation with HCV-related HCC, a significant number of HCC cases arising from HBV infection have a noncirrhotic liver background [21]. Viral factors including hepatitis B e antigen (HBeAg) status and genotype have been found to affect HCC development to varying degrees. Among these factors, persistent HBV replication indicated by the serum HBV DNA concentration is a predictor of HCC. A cohort study conducted in Taiwan showed that there is a biological gradient of risk for development of HCC based on the viral load at the start of the investigation [22]. This study involved more than 3700 subjects aged from 30 to 64 years with a follow-up period of more than 10 years. Whereas subjects with an initial viral load below $2000 \mathrm{IU} / \mathrm{ml}$ had the lowest risk of HCC, subjects in whom the viral load exceeded 20,000 IU/ $\mathrm{ml}$ had the highest risk of HCC. Based on this relationship between HBV load and HCC risk, a scoring system was developed to predict 3-, 5-, and 10-year HCC occurrence in untreated HBV-infected patients. This model has the merit of including such variables as sex, age, alanine aminotransferase level, HBeAg status, and HBV DNA quantity; these parameters are easily measured not only in tertiary hospitals but also in private clinics. Although the scoring system was validated by external data from Korea, Taiwan, and Hong Kong [23], it remains unclear whether the system can be applied to patients who have already received antiviral therapy. It seems that these viral factors form a complex web of interactions to initiate and promote HCC. In addition, the role of nonviral factors in HBV-related HCC is increasingly being recognized.

Following the case-control study indicating that chronic infection with HCV is strongly linked to HCC, many epidemiologic and experimental studies have confirmed that HCV is carcinogenic to humans [24-26]. In a prospective, community-based study that recruited 12,008 men, the risk of developing HCC was 20 -fold higher in HCV-positive subjects compared to HCV-negative subjects [27]. Despite significant progress in the treatment of HCV infection, including direct-acting antivirals, HCV infection is present in a large proportion of patients with cirrhosis and HCC in Europe and Japan. Moreover, the incidence of HCC has even increased in the United States, and studies have shown that HCV is the underlying cause of this trend [28]. Unlike the oncogenesis of HBV-related HCC, the oncogenesis of HCV-related HCC involves multiple steps from chronic inflammation to fibrosis, cirrhosis, and genetic changes, rather than resulting from a direct oncogenic property of HCV itself. Hence, most cases of HCV-related HCC involve underlying cirrhosis, and the annual incidence of HCC is $2-5 \%$ in cirrhotic patients. Interestingly, one study showed that HCC incidence increased with fibrosis stage in HCV-infected patients, although the incidence in those with fibrotic liver was lower than in those with cirrhosis [29]. Noninvasive measurement of liver fibrosis by transient elastography also revealed that there was a close relationship between LSM score and the presence of HCC in HCV-infected patients [30].

Excessive alcohol consumption is known to have an influence on the development of cirrhosis and liver cancer. Furthermore, alcohol interacts in a complex way with other environmental or host factors, such as HBV or HCV infection, to induce HCC. Hepatic steatosis 
evolves in all excessive drinkers; however, only about one-third of them develop significant necroinflammation and fibrosis and only about $10 \%$ progress to cirrhosis [31]. Among the latter, 1-2\% per year develop HCC [32]. A variety of factors relating to alcohol contribute to chronic hepatocyte damage, inflammation, and liver fibrosis. Among these, the induction of cytochrome P450 2E1 (a microsomal enzyme) and the resulting generation of reactive oxygen species and lipid peroxides are the pivotal mechanisms of alcohol-induced cirrhosis [33]. Recent evidence also suggests that tumor necrosis factor- $\alpha$ and toll-like receptor- 4 mediate hepatocyte injury and liver fibrosis from increased uptake of endotoxins produced by gut bacteria in alcohol-induced liver diseases [34]. A meta-analysis of 17 case-control and three cohort studies, including 2294 cases of HCC, reported a direct trend in risk of developing HCC with increasing alcohol consumption. The relative risk (RR) was 1.36 [95\% confidence interval (CI) 1.23-1.51] for $50 \mathrm{~g} /$ day and 1.86 (95\% CI 1.53-2.27) for $100 \mathrm{~g} /$ day [35].

Obesity and metabolic syndrome are the main causative factors of nonalcoholic fatty liver disease and NASH, which in turn probably contribute to increased incidence of HCC in Western countries. Multiple cohort or case-control studies have shown an association between the presence of diabetes and risk of HCC development [36-38]. A meta-analysis revealed that pre-existing diabetes was significantly associated with increased risk of HCC incidence (meta-RR 1.87, 95\% CI 1.15-2.27) and HCC-specific mortality (meta-RR 1.88, 95\% CI 1.39-2.55) compared with their nondiabetic counterparts, indicating that diabetes may be associated with elevated risk of both HCC incidence and mortality [39]. Phosphatase and tensin homolog (PTEN) is a multifunctional phosphatase and it is also a ubiquitously expressed tumor suppressor gene that downregulates PI3Ks [40]. The hepatocyte-specific PTEN-deficient mouse is an efficient model for NASH, in which PI3K-Akt activation leads to peroxisome proliferator-activated receptor $\gamma$ overexpression and increased oxidative DNA damage, resulting in hepatic tumorigenesis. It is reported that liver tumors are present in $66 \%$ of male and $30 \%$ of female PTEN-knockout mice by $40-44$ weeks of age [41]. Molecular studies have shown that a high concentration of insulin and insulin-like growth factor 1 in type 2 diabetics may have a hepatocarcinogenic effect [42]. In this regard, great attention is being paid to anti-diabetic drugs to reduce the risk of HCC development in diabetic patients. Indeed, several epidemiological studies have shown that treatment with metformin, an insulin sensitizer, was related to a decrease of HCC incidence in diabetic patients $[43,44]$.

Smoking is a potential risk factor of HCC development, which is to be expected based on the carcinogenic effects of several compounds in cigarette smoke and the role that liver plays in the metabolism of these compounds. In a study of 1,283,112 people who had been followed since they were cancer free, cigarette smoking was found to be associated with increased risk of mortality from HCC in men (RR 1.4; 95\% CI 1.3-1.6) [45]. Familial clustering of HCC cases is frequently observed, especially in Eastern countries, where HBV spread within the household is thought to be the reason why family history of HCC is a risk factor. A recent study also showed that a family history of liver cancer increases HCC risk independently of hepatitis even in a Western population [46].

\section{Target Population for HCC Surveillance}

Because cirrhosis is the strongest risk factor of HCC development, patients with compensated cirrhosis should enter surveillance programs irrespective of the etiology. However, it is not generally regarded to be cost-effective to perform surveillance tests on patients with decompensated cirrhosis. Although the risk of developing HCC in HBV-infected patients varies with the time since HBV acquisition, it is universally agreed that Asian or 
African patients need to undergo surveillance whether or not HBV is undergoing replication [47]. The issue of when to start surveillance in these patients requires accumulation of more data. Clearly, HCC surveillance must start at an earlier age in patients infected in the perinatal period or during childhood. However, currently, the lower age cutoff for surveillance is determined and individualized based on the prevalence of HCC, the availability of resources, and coexisting risk factors such as family history of HCC. The current guidelines of the American Association for the Study of Liver Diseases (AASLD) recommend surveillance only in cirrhotic patients with HCV, based on the HCV-related carcinogenic process from hepatitis, fibrosis, and cirrhosis to HCC. However, the incidence of noncirrhotic HCC in patients with HCV has been reported to be higher than expected [48]. Thus, it might be practical to perform surveillance of HCV carriers even if they do not definitely have cirrhosis. The accurate prediction of HCC development in the population at risk is an important issue for clinicians, and so some studies have combined various risk factors to estimate the probability of HCC occurrence [15, 23, 49, 50].

\section{Surveillance Tests}

\section{Ultrasonography}

Ultrasonography (US) is the mainstay of surveillance for early detection of HCC. It is safe, easy to use, comfortable for patients, and allows accurate identification of lesions by experienced operators. It also has the advantage of providing real-time images in a variety of scanning planes. However, the disadvantages of US examination are that the information obtained is largely dependent on the operator's skill and equipment and that it is difficult to detect small lesions in patients with obesity or severely nodular, contracted livers. The majority of studies on the accuracy of US surveillance do not report false-positive results, and it is often unclear whether US was used for surveillance or diagnosis [51-53]. In a meta-analysis that evaluated the performance of surveillance US, sensitivity and specificity were both $94 \%$ in detecting all stages of HCC, whereas the sensitivity was $63 \%$ in early HCC defined as one nodule $<5 \mathrm{~cm}$ or three nodules each $<3 \mathrm{~cm}$ in diameter without gross vascular invasion (the Milan criteria) [54]. Therefore, the sensitivity of surveillance US is much lower for single small $(<2 \mathrm{~cm}) \mathrm{HCC}$, which are the best candidates for curative resection or radiofrequency ablation. Double-contrast US using intravenously injected Sonazoid can identify Kupffer cell defects and arterial blood flow, and so is reported to have a better performance in detection of small HCC than conventional B-mode US, especially in Japan [55]. This new technique is promising as it may overcome the limitations of US in coarse liver; however, the technique requires further validation in other countries. The effectiveness of computed tomography (CT) or magnetic resonance imaging (MRI) has not been well studied. In a retrospective study of 225 HCC patients who underwent liver transplantation, the sensitivity of US, CT, and MRI in detecting nodules $<2 \mathrm{~cm}$ was $21 \%, 40 \%$, and $47 \%$. Whereas, the specificities of the three modalities for lesions $<2 \mathrm{~cm}$ were $82 \%, 74 \%$, and $77 \%$, respectively [56]. Due to the radiation hazard of CT, the long scanning time, the higher cost, and the higher false-positive rate, it is generally not acceptable to routinely use this modality in HCC surveillance. Nevertheless, alternative imaging modalities, including CT or MRI with modified scanning protocols to reduce radiation exposure, scan times, and costs, might be necessary for selected cirrhotic patients for whom US is not an adequate tool in HCC surveillance. 


\section{Alpha-Fetoprotein (AFP)}

AFP is the most commonly used serological marker for HCC, although the practice guidelines of the AASLD exclude AFP from surveillance testing, leaving US as the only option [47]. There are insufficient data on the accuracy of AFP in HCC surveillance. However, the observation that $80 \%$ of patients with small HCCs show no increase in AFP level indicates that this biomarker is not optimal for the detection of early HCC. In a recent study of 1031 patients with chronic hepatitis $\mathrm{C}$ who had been recruited in the Hepatitis C Antiviral Longterm Treatment Against Cirrhosis (HALT-C) trial, the performance of AFP as a surveillance biomarker was assessed in 39 HCC patients and 77 matched controls. With a cutoff of $20 \mathrm{ng} /$ $\mathrm{ml}$, the sensitivity and specificity of AFP were $47 \%$ and $75 \%$ at 12 months before diagnosis of HCC. Whereas, the sensitivity was just $3 \%$ and the specificity was $100 \%$ with a cutoff of $200 \mathrm{ng} / \mathrm{ml}$ [57]. Nonetheless, many physicians worldwide use serum AFP measurement combined with US to reduce the chance of missing small lesions against the cirrhotic background; these lesions are hard to detect even for experienced operators. It does not seem practical to exclude AFP measurement from HCC surveillance in the absence of prospective studies comparing US+AFP with US alone. In particular, the importance of serological surveillance needs to be stressed in developing countries where the availability of US surveillance is quite low.

\section{Des-Gamma-Carboxy Prothrombin (DCP)}

DCP is a well-known and widely used tumor marker for HCC, especially in Korea and Japan. Many studies have evaluated the diagnostic accuracy of DCP compared with that of AFP [58-60]. In a Korean study, the performances of AFP and DCP were assessed during HCC surveillance with cutoffs of $20 \mathrm{ng} / \mathrm{ml}$ and $40 \mathrm{mAU} / \mathrm{ml}$, respectively [61]. The sensitivity and specificity of AFP were $57.5 \%$ and $88.0 \%$, while those of DCP were $51.9 \%$ and $97.0 \%$, respectively. In a multicenter study carried out in the United States, DCP had a higher sensitivity (74\%) than AFP (59\%) at the cutoff recommended by the practice guidelines. However, when the cutoff level was determined by the receiver operating characteristic curve, AFP showed a higher sensitivity (70\%) than DCP (66\%) [58]. DCP also has limitations as an effective biomarker for HCC surveillance. The first is that its sensitivity is unacceptably low for small HCCs. It was found that the sensitivity of DCP was only $35.0 \%$ and $39.3 \%$ in HCCs smaller than $2 \mathrm{~cm}$ and smaller than $3 \mathrm{~cm}$, respectively [62]. The second is that DCP is usually regarded as a marker for poor prognosis or for HCC with vascular invasion, which makes it unlikely that increases in DCP levels are an indication of early HCC [63-65]. DCP is complementary to AFP, and so the serum level of this marker may be increased in AFP-negative HCC. The measurement of both AFP and DCP for HCC surveillance is a routine clinical practice in Japan to improve the detection rate of early HCC $[66,67]$. So far, there is no concrete evidence that shows the superiority of AFP+DCP compared to AFP alone in HCC surveillance. Thus, a prospective study is necessary to compare the performance of AFP+DCP with that of AFP alone in cirrhotic patients in the setting of a surveillance program.

\section{Fucosylated Fraction of AFP}

The fucosylated fraction of AFP (AFP-L3) is known to be more specific for HCC than total AFP is [68]. However, the conventional assay for AFP-L3 is unstable, and AFP-L3 may be undetectable when the serum AFP level is $<20 \mathrm{ng} / \mathrm{ml}$, although the clinical usefulness of this biomarker has been reported. Recent technical progress has improved the analytical sensitivity of this assay by using novel and advanced microfluidics-based separation science [69]. The diagnostic performance of AFP-L3 assayed by this highly sensitive method (hs-AFP-L3) was evaluated in 396 HCC and 270 non-HCC control patients whose AFP levels were $<20$ $\mathrm{ng} / \mathrm{ml}$. The sensitivity and specificity of hs-AFP-L3 were $41.5 \%$ and $85.1 \%$, respectively, at 
a cutoff level of 5\%, which was a significant increase compared to the $7.0 \%$ sensitivity of the conventional AFP-L3 assay[70]. It is noteworthy that the detection rate of early HCC in Japan is more than $60 \%$, which is the highest in the world [66]. This high rate of early HCC detection may be due in part to intensive surveillance programs using three biomarkers with different characteristics, i.e., AFP, DCP, and AFP-L3 [67]. Besides improved specificity and cost-effectiveness, combined measurement of tumor markers increases the chance of detecting small HCCs. The utility of hs-AFP-L3 in HCC surveillance needs to be validated by a prospective study evaluating the individual sensitivities and specificities of US, AFP, DCP, and AFP-L3.

\section{Other Biomarkers}

Osteopontin (OPN) is a secreted phosphoprotein that binds alphaV-integrins and cluster of differentiation 44 families of receptors [71]. OPN is reportedly not only associated with tumor invasion, progression, and metastasis in various cancers [72], it is also a potential biomarker for detection of early HCC. In a recent study, plasma OPN was better than AFP at differentiating HCC from cirrhosis (or viral hepatitis) in all subgroups of HBV-HCC, HCV-HCC, and early HCC [73]. Furthermore, the observation that OPN was already elevated 12 months before HCC diagnosis in a surveillance cohort is promising and implies that this marker could be used as a surveillance test.

Glypican-3 (GPC-3) is normally involved in the regulation of cell proliferation and survival during embryonic development and functions as a tumor suppressor. The specificity of GPC-3 is known to be $100 \%$ because it is absent in hepatocytes of healthy subjects and patients with nonmalignant hepatic pathology. However, its low sensitivity (50\% in HCC) is an obstacle to its use as a surveillance biomarker [74].

\section{Surveillance Interval}

Based on the doubling time of untreated HCC, it is generally recommended that surveillance should be performed at intervals of 6-12 months. This interval range is based on the assumption that a lesion that was not detected during the previous surveillance US examination will be detected at the smallest practical detection size at the next examination. The concept of "enhanced follow-up" should be differentiated from surveillance. Because the surveillance interval should be determined based on the characteristics of tumor growth, not by the risk of developing HCC, it is not relevant to shorten the surveillance interval even when a patient has a high probability of developing HCC. On the other hand, enhanced follow-up means that special attention can be paid to a suspicious lesion found on the previous surveillance test. For instance, repeated US or CT scan might be performed for that suspicious lesion a few weeks or months later. Enhanced follow-up should also be applied when tumor marker levels are gradually increasing during surveillance. Currently, it seems that the 6-month strategy is superior to the 12-month strategy in terms of early tumor detection and overall survival. Patient survival in the 6-month surveillance group was found to be higher than that in the 12-month group in a prospective Korean study of predominantly HBV-infected subjects [75]. A Western study also confirmed this result by demonstrating a better cancer stage and 5-year survival rate in the group undergoing semiannual surveillance in predominantly HCV-infected patients [76]. This raises the question as to whether shortening the surveillance interval from 6 months to 3 months would lead to a further improvement in outcome. The answer appears to be "no," because a 3-monthly US surveillance program did not provide any advantage over a 6-monthly pro- 
Table 1. Characteristics and outcomes of HCC surveillance in different geographic areas

\begin{tabular}{|c|c|c|c|c|c|c|}
\hline Author & $\begin{array}{c}\text { Geographic } \\
\text { area }\end{array}$ & Sample size & Etiology & $\begin{array}{l}\text { Study } \\
\text { design }\end{array}$ & $\begin{array}{c}\text { Survival in } \\
\text { surveillance group }\end{array}$ & $\begin{array}{l}\text { Survival in } \\
\text { control group }\end{array}$ \\
\hline $\begin{array}{l}\text { Zhang } \\
\text { et al. [78] }\end{array}$ & Asia & $\begin{array}{l}\text { Screening } 9373 \\
\text { Control } 9443\end{array}$ & HBV & RCT & $\begin{array}{c}\text { 5-yr survival } \\
46.4 \%\end{array}$ & $\begin{array}{c}5 \text {-yr survival } \\
0 \%\end{array}$ \\
\hline $\begin{array}{l}\text { Yuen } \\
\text { et al. [79] }\end{array}$ & Asia & $\begin{array}{l}\text { Screening } 142 \\
\text { Control } 164\end{array}$ & HBV & $\mathrm{CC}$ & $\begin{array}{l}\text { Significantly higher } \\
\text { survival than control }\end{array}$ & \\
\hline $\begin{array}{l}\text { Tong } \\
\text { et al. [81] }\end{array}$ & $\begin{array}{l}\text { United } \\
\text { States }\end{array}$ & $\begin{array}{l}\text { Screening } 26 \\
\text { Control } 52\end{array}$ & HBV & $\mathrm{CC}$ & $\begin{array}{c}\text { 5-yr survival } \\
35.7 \%\end{array}$ & $\begin{array}{c}\text { 5-yr survival } \\
16.3 \%\end{array}$ \\
\hline $\begin{array}{l}\text { Yang } \\
\text { et al. [84] }\end{array}$ & $\begin{array}{l}\text { United } \\
\text { States }\end{array}$ & $\begin{array}{l}\text { Screening } 136 \\
\text { Control } 307\end{array}$ & $\begin{array}{c}\mathrm{HCV} \\
\text { Alcohol }\end{array}$ & $\mathrm{CC}$ & $\begin{array}{l}\text { Significantly higher } \\
\text { survival than control }\end{array}$ & \\
\hline $\begin{array}{l}\text { Trevisani } \\
\text { et al. [85] }\end{array}$ & Europe & $\begin{array}{l}\text { Screening } 158 \\
\text { Symptomatic } 67\end{array}$ & $\begin{array}{l}\mathrm{HCV} \\
\mathrm{HBV}\end{array}$ & $\mathrm{CC}$ & $\begin{array}{l}\text { Median survival } \\
24 \text { months }\end{array}$ & $\begin{array}{l}\text { Median survival } \\
7 \text { months }\end{array}$ \\
\hline $\begin{array}{l}\text { Ando } \\
\text { et al. [86] }\end{array}$ & Asia & $\begin{array}{l}\text { Screening } 91 \\
\text { Symptomatic } 181\end{array}$ & $\mathrm{HCV}$ & $\mathrm{CC}$ & $\begin{array}{c}5 \text {-yr survival } \\
52 \%\end{array}$ & $\begin{array}{c}5 \text {-yr survival } \\
23 \%\end{array}$ \\
\hline
\end{tabular}

$\mathrm{CC}=$ case-control.

gram. Instead, it only increased costs due to false-positive results [77].

\section{Benefits of HCC Surveillance}

Many studies have revealed that surveillance increases the survival rate in HBV carriers and patients with cirrhosis by detecting HCC at early stages that are amenable to curative treatments such as resection, ablation, and liver transplantation [51, 52, 75, 76, 78-81]. A randomized trial conducted in China is the only study to have investigated the outcome of HCC surveillance [78]. In that study, patients with chronic hepatitis B were randomized to a surveillance arm or a no surveillance arm. Despite several limitations, such as resection as the main therapy, suboptimal compliance with surveillance, and HBV as the predominant etiology, there was a 37\% reduction in HCC-related mortality in the surveillance arm. The extent of the benefits provided by surveillance programs in cirrhotic patients differs because of the heterogeneity of the study population and the intensity of the surveillance tests employed. In a study of 1480 HCV-infected patients living in the United States, the use of either AFP or US surveillance during the 0-6 months or the 7-24 months before HCC diagnosis was associated with a lower mortality risk (hazard ratio $0.71,95 \% \mathrm{CI} 0.62$ to 0.82 ) compared with no surveillance [82]. A retrospective Hong Kong study also found a survival gain resulting from surveillance [79]. It compared 143 patients with HCC diagnosed during surveillance with 164 patients who were diagnosed with symptomatic HCC; the operability and feasibility of treatment by transarterial chemoembolization in patients who had undergone surveillance $(26.8 \%$ and $45.1 \%)$ were significantly higher than in patients who had not undergone surveillance $(7.9 \%$ and $32.3 \%)$. The cumulative survival was also higher in patients who had undergone surveillance. Table 1 summarizes the characteristics and out- 
comes of HCC surveillance performed in different geographic areas. Most previous studies involve intrinsic lead-time bias because of their retrospective nature; therefore, a welldesigned randomized controlled trial (RCT) is necessary to confirm the effectiveness of HCC surveillance. However, a recent study reported that it may be impossible to conduct a RCT on HCC surveillance because $99.5 \%$ of patients informed of the benefits and risks would not participate in such a trial. Thus, the accumulated evidence currently suggests that surveillance for early HCC detection should no longer be just a recommendation, but should become a standard of care in clinical practice [83].

\section{Future Perspectives and Conclusions}

The current strategy of HCC surveillance faces two issues. The first is whether the recommendation of US (+AFP) examination is being strictly adhered to for cirrhotic patients. Unfortunately, data on this subject are not readily available from Asian countries, where the prevalence of HCC is the highest in the world. In a study carried out in the United States, around $42.0 \%$ of cirrhotic patients received one or more surveillance tests within the first year after diagnosis of cirrhosis. However, a decline in the percentage of patients undergoing surveillance was observed in the following 2-4 years. In addition, among cirrhotic patients with at least 2 years of follow-up, routine surveillance occurred just in $12.0 \%$, inconsistent surveillance in $58.5 \%$, and no surveillance in $29.5 \%$ [87]. These data indicate that adherence to HCC surveillance is still suboptimal. The second issue is how to improve the performance of surveillance testing to detect early HCC. Numerous biomarkers have been identified by advanced proteomics techniques such as mass-spectrometry in laboratories, but these have failed to enter clinical use. In this regard, small noncoding genetic molecules (microRNAs) have emerged as novel biomarkers for diagnosis of early HCC, and several types of microRNAs in blood have already been validated as being useful in discriminating HCC from cirrhosis [88].

The outcome of HCC surveillance is still not satisfactory in the opinion of most physicians; further progress is needed to achieve higher rates of early HCC detection and improved patient survival. There is a real difference in the viewpoints of Eastern and Western physicians with regard to HCC surveillance, especially in terms of whether to use biomarkers. The differences in health care policies and systems, including insurance cover, determine the priorities of early cancer detection and the cost-effectiveness of HCC surveillance. Certainly, comprehensive and balanced guidelines considering both points of view are required [89].

\section{Acknowledgment}

This study was funded partly by a grant from the Korean Healthcare Technology R\&D Project, Ministry of Health and Welfare, Republic of Korea (A102065).

\section{References}

1 Ferlay J, Shin HR, Bray F, Forman D, Mathers CD, Parkin D: GLOBOCAN 2008, Cancer Incidence and Mortality Worldwide: IARC CancerBase No. 10. Lyon, France: International Agency for Research on Cancer; Year. Available at: http://globocan.ia.rc.fr.2010. Last accessed 8/17/2010.

2 Ahmed F, Perz JF, Kwong S, Jamison PM, Friedman C, Bell BP: National trends and disparities in the incidence of hepatocellular carcinoma, 1998-2003. Prev Chronic Dis 2008;5:A74 Available at http://www. 
cdc.gov/pcd/issues/2008/jul/07_0115.htm Accessed on May 19, 2011.

3 Stravitz RT, Heuman DM, Chand N, et al: Surveillance for hepatocelluar carcinoma in patients with cirrhosis improves outcome. Am J Med 2008;121:119-126.

4 Liu JH, Chen PW, Asch SM, Busuttil RW, Ko CY: Surgery for hepatocellular carcinoma: does it improve survival? Ann Surg Oncol 2004;11:298-303.

5 Srinivas PR, Kramer BS, Srivastava S: Trends in biomarker research for cancer detection. Lancet Oncol 2001;2:698-704.

6 Ferlay J, Shin SR, Bray F, Forma D, Mathers C, Parkin DM: Estimates of worldwide burden of cancer in 2008: GLOBOCAN 2008. Int J Cancer 2010;127:2893-2917.

7 Jemal A, Bray F, Center MM, Ferlay J, Ward E, Forman D: Global cancer statistics. CA Cancer J Clin 2011;61:6990.

8 Tanaka M, Katayama F, Kato H, et al: Hepatitis B and C virus infection and hepatocellular carcinoma in China: a review of epidemiology and control measures. J Epidemiol 2011;21:401-416.

9 Tanaka H, Imai Y, Hiramatsu N, et al: Declining incidence of hepatocellular carcinoma in Osaka, Japan, from 1990 to 2003. Ann Intern Med 2008;148:820-826.

10 Altekruse SF, McGlynn KA, Dickie LA, Kleiner DE: Hepatocellular carcinoma confirmation, treatment, and survival in surveillance, epidemiology, and end results registries, 1992-2008. Hepatology 2012;55:476482.

11 FattovichG: Natural history and prognosis of hepatitis B. Semin Liver Dis 2003;23:47-58.

12 El-Serag HB, Rudolph KL: Hepatocellular carcinoma: epidemiology and molecular carcinogenesis. Gastroenterology 2007;132:2557-2576.

13 Han KH, Ahn SH: How to predict HCC development in patients with chronic B viral liver disease? Intervirology 2005;48:23-28.

14 Parsons CJ, Takashima M, Rippe RA: Molecular mechanisms of hepatic fibrogenesis. J Gastroenterol Hepatol 2007;22(Suppl 1):S79-S84.

15 FriedmanSL: Mechanism of hepatic fibrogenesis. Gastroenterology 2008;134:1655-1669.

16 Jung KS, Kim SU, Ahn SH, et al: Risk assessment of hepatitis B virus-related hepatocellular carcinoma development using liver stiffness measurement (FibroScan). Hepatology 2011;53:885-894.

17 Mazzaferro V, Regalia E, Doci R, et al: Liver transplantation for the treatment of small hepatocellular carcinoma in patients with cirrhosis. N Engl J Med 1996;334:693-699.

18 Bosch FX, Ribes J, Diaz M, Cleries R: Primary liver cancer: worldwide incidence and trends. Gastroenterology 2004;127:S5-S16.

19 Feitelson MA, Lee J: Hepatitis B virus integration, fragile sites, and hepatocarcinogenesis. Cancer Lett 2007;252:157-170.

20 Wang HC, Huang W, Lai MD, Shu IJ: Hepatitis B virus pre-S mutants, endoplasmic reticulum stress and hepatocarcinogenesis. Cancer Sci 2006;97:683-688.

21 Beasley RP, Hwang LY, Lin CC, et al: Hepatocellular carcinoma and hepatitis B virus. A prospective study of 22,700 men in Taiwan. Lancet 1981;2:1129-1133.

22 Chen CJ, Yang HI, Su J, et al REVEAL-HBV Study Group: Risk of hepatocellular carcinoma across a biological gradient of serum hepatitis B virus DNA level. JAMA 2006;295:65-73.

23 Yang HI, Yuen MF, Chan HL, Han KH, Chen PJ, Kim DY, et al: Risk estimation for hepatocellular carcinoma in chronic hepatitis B (REACH-B): development and validation of a predictive score. Lancet Oncol 2011;12:568-574.

24 Kew MC, Houghton M, Choo QL, et al: Hepatitis C virus antibodies in southern African blacks with hepatocellular carcinoma. Lancet 1990;1990:335-873-874.

25 Trichopoulos D, Bamia C, Lagiou P, et al: Hepatocellular carcinoma risk factors and disease burden in a European cohort: a nested case-control study. J Natl Cancer Inst 2011;103:1686-1695.

26 Matsuzaki K, Murata M, Yoshida K, Sekimoto G, Uemura Y, Sakaida N, et al: Chronic inflammation associated with hepatitis $C$ virus infection perturbs hepatic transforming grow th factor beta signaling, promoting cirrhosis and hepatocellular carcinoma. Hepatology 2007;46:48-57.

27 Sun CA, Wu DM, Lin CC, et al: Incidence and cofactors of hepatitis C virus-related hepatocellular carcinoma: a prospective study of 12,008 men in Taiwan. Am J Epidemiol 2003;157:674-682.

28 Davila JA, Morgan RO, Shaib Y, et al: Hepatitis C infection and the increasing incidence of hepatocellular carcinoma: a population based study. Gastroenterology 2004;127:1372-1380.

29 Lok AS, Seeff LB, Morgan RT, et al: Incidence of hepatocellular carcinoma and associated risk factors in hepatitis C-related advanced liver disease. Gastroenterology 2009;136:138-148.

30 Masuzaki R, Tateishi R, Yoshida H, et al: Risk assessment of hepatocellular carcinoma in chronic hepatitis C patients by transient elastography. J Clin Gastroenterol 2008;42:839-843.

31 Bellentani S, Saccoccio G, Costa G, et al: Drinking habits as cofactors of risk for alcohol induced liver damage. Gut 1997;41:845-850.

32 Seitz HK, Stickel F: Molecular mechanisms of alcohol-mediated carcinogenesis. Nat Rev Cancer 2007;7:599612.

33 LieberCS: Alcoholic fatty liver: its pathogenesis and mechanism of progression to inflammation and fibrosis. Alcohol 2004;34:9-19.

34 Altamirano J, Bataller R: Alcoholic liver disease: pathogenesis and new targets for therapy. Nat Rev Gastroenterol Hepatol 2011;8:491-501.

35 Bagnardi V, Blangiardo M, La Vecchia C, Corrao G: A meta-analysis of alcohol drinking and cancer risk. Br J Cancer 2001;85:1700-1705. 
36 Chen CL, Yang HI, Yang WS, et al: Metabolic factors and risk of hepatocellular carcinoma by chronic hepatitis B/C infection: a follow-up study in Taiwan. Gastroenterology 2008;135:111-121.

37 Lai MS, Hsieh MS, Chiu YH, Chen TH: Type 2 diabetes and hepatocellular carcinoma: a cohort study in high prevalence area of hepatitis virus infection. Hepatology 2006;43:1295-1302.

38 Davila JA, Morgan RO, Shaib Y, McGlynn KA, El-Serag HB: Diabetes increases the risk of hepatocellular carcinoma in the United States: a population based case control study. Gut 2005;54:533-539.

39 Yang WS, Va P, Bray F, et al: The role of pre-existing diabetes mellitus on hepatocellular carcinoma occurrence and prognosis: a meta-analysis of prospective cohort studies. PLoS ONE 2011;6:e27326.

40 Li J, Yen C, Liaw D, et al: PTEN, a putative protein tyrosine phosphatase gene mutated in human brain, breast, and prostate cancer. Science 1997;275:1943-1947.

41 Watanabe S, Horie Y, Kataoka E, et al: Non-alcoholic steatohepatitis and hepatocellular carcinoma: lessons from hepatocyte-specific phosphatase and tensin homolog (PTEN)-deficient mice. J Gastroenterol Hepatol 2007; (22, Suppl 1)S96-S100.

42 Calle EE, Kaaks R: Overweight, obesity and cancer: epidemiological evidence and proposed mechanisms. Nat Rev Cancer 2004;4:579-591.

43 Hassan MM, Curely SA, Li D, et al: Association of diabetes duration and diabetes treatment with the risk of hepatocellular carcinoma. Cancer 2010;116:1938-1946.

44 Lai SW, Chen PC, Liao KF, Muo CH, Lin CC, Sung FC: Risk of hepatocellular carcinoma in diabetic patients and risk reduction associated with anti-diabetic therapy: a population-based cohort study. Am J Gastroenterol 2012;107:46-52.

45 Jee SH, Ohrr H, Sull JW, Samet JM: Cigarette smoking, alcohol drinking, hepatitis B, and risk for hepatocellular carcinoma in Korea. J Natl Cancer Inst 2004;96:1851-1856.

46 Turati F, Edefonti V, Talamini R, et al: Family history of liver cancer and hepatocellular carcinoma. Hepatology [Epub ahead of print].

47 Bruix J, Sherman M: Management of heaptocellular carcinoma. Hepatology 2005;42:1208-1236.

48 Shrager B, Jibara G, Schwartz M, Roayaie S. Resection of hepatocellular carcinoma with cirrhosis. Ann Surg [Epub ahead of print].

49 Yuen MF, Tanaka Y, Fong DY, et al: Independent risk factors and predictive score for the development of hepatocellular carcinoma in chronic hepatitis B. J Hepatol 2009;50:80-88.

50 Kurosaki M, Hiramatsu N, Sakamoto M, et al: Data mining model using simple and readily available factors could identify patients at high risk for hepatocellular carcinoma in chronic hepatitis C. J Hepatol 2012;56:602-608.

51 Bolondi L, Sofia S, Siringo S, et al: Surveillance programme of cirrhotic patients for early diagnosis and treatment of hepatocellular carcinoma: a cost effectiveness analysis. Gut 2001;48:251-259.

52 Sangiovanni A, Del Ninno E, Fasani P, et al: Increased survival of cirrhotic patients with a hepatocellular carcinoma detected during surveillance. Gastroenterology 2004;126:1005-1014.

53 Sangiovanni A, Prati GM, Fasani P, et al: The natural history of compensated cirrhosis due to hepatitis C virus: a 17-year cohort study of 214 patients. Hepatology 2006;43:1303-1310.

54 Singal A, Volk ML, Waljee A, et al: Meta-analysis: surveillance with ultrasound for early-stage hepatocellular carcinoma in patients with cirrhosis. Aliment Pharmacol Ther 2009;30:37-47.

55 KudoM: Diagnostic imaging of hepatocellular carcinoma: recent progress. Oncology 2011;81(Suppl 1):73-85.

56 Yu NC, Chaudhari V, Raman SS, Lassman C, Tong MJ, Busuttil RW, Lu DS. CT and MRI improve detection of hepatocellular carcinoma, compared with ultrasound alone, in patients with cirrhosis. Clin Gastroenterol Hepatol 2011;9:161-167.

57 Lok AS, Sterling RK, Everhart JE, et al: Des- $\gamma$-carboxy prothrombin and $\alpha$-fetoprotein as biomarkers for the early detection of hepatocellular carcinoma. Gastroenterology 2010;138:493-502.

58 Marrero JA, Feng Z, Wang Y, et al: Alpha-fetoprotein, des-gamma carboxyprothrombin, and lectin-bound alpha-fetoprotein in early hepatocellular carcinoma. Gastroenterology 2009;137:110-118.

59 Yamamoto K, Imamura H, Matsuyama Y, et al: Significance of alpha-fetoprotein and des-gamma-carboxy prothrombin in patients with hepatocellular carcinoma undergoing hepatectomy. Ann Surg Oncol 2009;16:2795-2804.

60 Durazo FA, Blatt LM, Corey WG, et al: Des-gamma-carboxyprothrombin, alpha-fetoprotein and AFPL3 in patients with chronic hepatitis, cirrhosis, and hepatocellular carcinoma. J Gastroenterol Hepatol 2008;23:1541-1548.

61 Yoon YJ, Han KH: Kim do Y. Role of serum prothromboin induced by vitamin K absence or antagonist-II in the early detection of hepatocellular carcinoma in patients with chronic hepatitis B virus infection. Scand J Gastroenterol 2009;44:861-866.

62 Okuda H, Nakanishi T, Takatsu K, et al: Measurement of serum levels of des-gamma-carboxy prothrombin in patients with hepatocellular carcinoma by a revised enzy me immunoassay kit with increased sensitivity. Cancer 1999;85:812-818.

63 Kobayashi M, Ikeda K, Kawamura Y, et al: High serum des-gamma-carboxy prothrombin level predicts poor prognosis after radiofrequency ablation of hepatocellular carcinoma. Cancer 2009;115:571-580.

64 Koike Y, Shiratori Y, Sato S, et al: Des-gamma-carboxy prothrombin as a useful predisposing factor for the development of portal venous invasion in patients with hepatocellular carcinoma: a prospective analysis of 227 patients. Cancer 2001;91:561-569.

65 Shirabe K, Itoh S, Yoshizumi T, et al: The predictors of microvascular invasion in candidates for liver transplantation with hepatocellular carcinoma-with special reference to the serum levels of des-gamma- 
carboxy prothrombin. J Surg Oncol 2007;95:235-240.

66 IzumiN: Diagnostic and treatment algorithm of the Japanese Society of Hepatology: A consensus-based practice guideline. Oncology 2010;78(suppl 1):78-86.

67 KudoM: Real practice of hepatocellular carcinoma in Japan: Conclusions of the Japan Society of Hepatology 2009 Kobe Congress. Oncology 2010;78(suppl 1):180-188.

68 Taketa K, Endo Y, Sekiya C, et al: A collaborative study for the evaluation of lectin-reactive $\alpha$-fetoproteins in early detection of hepatocellular carcinoma. Cancer Res 1993;53:5419-5423.

69 Kagebayashi C, Yamaguchi I, Akinaga A, et al: Automated immunoassay system for AFP-L3\% using on-chip electrokinetic reaction and separation by affinity electrophoresis. Anal Biochem 2009;388:306-311.

70 Toyoda H, Kumada T, Tada T, et al: Clinical utility of highly sensitive Lens culinaris agglutinin-reactive alpha-fetoprotein in hepatocellular carcinoma patients with alpha-fetoprotein $<20 \mathrm{ng} / \mathrm{mL}$. Cancer Sci 2011;102:1025-1031.

71 El-TananiMK: Role of osteopontin in cellular signaling and metastatic phenotype. Front Biosci 2008;13:4276-4284.

72 Anborgh PH, Mutrie JC, Tuck AB, Chambers AF: Role of the metastasis-promoting protein osteopontin in the tumour microenvironment. J Cell Mol Med 2010;14:2037-2044.

73 Shang S, Plymoth A, Ge S, et al: Identification of osteopontin as a novel marker for early hepatocellular carcinoma. Hepatology 2012;55:483-490.

74 Nakatsura T, Yoshitake Y, Senju S, et al: Glypican-3, overexpressed specifically in human hepatocellular carcinoma, is a novel tumor marker. Biochem Biophys Res Commun 2003;306:16-25.

75 Kim DY, Han KH, Ahn SH, et al: Semiannual surveillance for hepatocellular carcinoma improved survival compared to annual surveillance (Korean experience). Hepatology 2007;46(suppl 1):403A.

76 Santi V, Trevisani F, Gramenzi A, et al: Semiannual surveillance is superior to annual surveillance for the detection of early hepatocellular carcinoma and patient survival. J Hepatol 2010;53:291-297.

77 Trinchet JC, Chaffaut C, Bourcier C, et al: Ultrasonography surveillance of hepatocellular carcinoma of hepatocellular carcinoma in cirrhosis: a randomized trial comparing 3- and 6-month periodicities. Hepatology 2011;54:1987-1997.

78 Zhang BH, Yang BH, Tang ZY: Randomized controlled trial of screening for hepatocellular carcinoma. J Cancer Res Clin Oncol 2004;130:417-422.

79 Yuen MF, Cheng CC, Lauder IJ, et al: Early detection of hepatocellular carcinoma increases the chance of treatment: Hong Kong experience. Hepatology 2000;31:330-335.

80 Marrero JA, Fontana RJ, Su GL, et al: NAFLD may be a common underlying liver disease in patients with hepatocellular carcinoma in the United States. Hepatology 2002;36:1349-1354.

81 Tong MJ, Sung HE, Hsien C, Lu DS: Surveillance for hepatocellular carcinoma improves survival in AsianAmerican patients with hepatitis B: results from a community-based clinic. Dig Dis Sci 2010;55:826-835.

82 El-Serag HB, Kramer JR, Chen JG, et al: Effectiveness of AFP and ultrasound tests on hepatocellular carcinoma mortality in HCV-infected patients in the USA. Gut 2011;60:992-997.

83 Amarapurkar D, Han KH, Chan HL, et al: Application of surveillance programs for hepatocellular carcinoma in the Asia-Pacific Region. J Gastroenterol Hepatol 2009;24:955-961.

84 Yang JD, Harmsen WS, Slettedahl SW, et al: Factors that affect risk for hepatocellular carcinoma and effects of surveillance. Clin Gastroenterol Hepatol 2011;9:617-623.

85 Trevisani F, Cantarini MC, Labate AM, et al: Surveillance for hepatocellular carcinoma in elderly Italian patients with cirrhosis: effects on cancer staging and patient survival. Am J Gastroenterol 2004;99:14701476.

86 Ando E, Kuromatsu R, Tanaka M, et al: Surveillance program for early detection of hepatocellular carcinoma in Japan: results of specialized department of liver disease. J Clin Gastroenterol 2006;40:942-948.

87 Davila JA, Henderson L, Kramer JR, et al: Utilization of surveillance for hepatocellular carcinoma among hepatitis C virus-infected veterans in the United States. Ann Intern Med 2011;154:85-93.

88 Qi P, Cheng SQ, Wang H, Li N, Chen YF, Gao CF: Serum microRNAs as biomarkers for hepatocellular carcinoma in Chinese patients with chronic hepatitis B virus infection. PLoS ONE 2011;6:228486.

89 Kim do Y, Kim JW, Kuromatsu R, et al.: Controversies in surveillance and early diagnosis of hepatocellular carcinoma. Oncology 2011;81(suppl 1):56-60. 